\begin{tabular}{|l|l|}
\hline Postprint Version & 1.0 \\
\hline Journal website & $\underline{\text { http://dx.doi.org/10.1016/j.ijnurstu.2010.02.010 }}$ \\
\hline Pubmed link & $\underline{\text { http://www.ncbi.nlm.nih.gov/pubmed/20371058 }}$ \\
\hline DOI & $10.1016 /$ j.ijnurstu.2010.02.010 \\
\hline
\end{tabular}

This is a NIVEL certified Post Print, more info at http://www.nivel.eu

\title{
The relationship between organizational culture of nursing staff and quality of care for residents with dementia: Questionnaire surveys and systematic observations in nursing homes
}

\author{
A.P.A. VAN BEEK ${ }^{\text {A }}$, , D.L. GERRITSEN ${ }^{\text {B }}$, \\ a NIVEL: Netherlands Institute for Health Services Research, Otterstraat 118-124, PO Box 1568, 3500 BN \\ Utrecht, The Netherlands \\ ${ }^{\mathrm{b}}$ Radboud University Nijmegen Medical Centre, Department of Primary and Community Care: Centre For \\ Family Medicine, Geriatric Care and Public Health, PO Box 9101, 6500 HB Nijmegen, The Netherlands
}

\begin{abstract}
Background: Since the 1990s, several studies have shown that organizational culture is an important characteristic in long-term care. However, at the moment little is known about organizational culture and its relationship with quality of care.

Objectives: In this study, the relationship between organizational culture and quality of care in long-term care was investigated using the competing values framework. Thereto, two independent measurements of quality of care were applied: the perceived quality of care by nursing staff of dementia units and the observed quality of care on the units by researchers.

Design: The study used a cross-sectional design.

Settings: Data were collected on 11 dementia units in 11 Dutch nursing homes.

Participants: All nursing staff on the units were asked to complete a questionnaire, of whom 248 staff members responded. The average response rate on the 11 units was $63 \%$.

Methods: Data were collected during two days of field-work on each unit. Systematic observations were performed, and questionnaires were distributed among nursing staff. Data were analyzed using multilevel analyses.

Results: Organizational culture was related to both perceived and observed quality of care on the units. Units that are characterized by a clan culture provide better quality of care, both in the eyes of the nursing staff as in the eyes of outsiders. Market culture, compared to clan culture, is negatively related to quality of care in this sample.

Conclusions: The results indicate that organizational culture in long-term dementia care is important for organizational performance.
\end{abstract}

\section{WHAT IS ALREADY KNOWN ABOUT THE TOPIC?}

- Organizational culture is an important characteristic of long-term care. 
- A strong framework of organizational culture that is often applied in healthcare research is the competing values framework. The framework distinguishes clan cultures, market cultures, adhocracy cultures and hierarchy cultures.

- Although there may be a relationship between culture and performance, articulating the nature of it is difficult.

What this paper adds

- Organizational culture was related to both perceived and observed quality of care on long-term care dementia units.

- Nursing staff seem to base their judgment of the general quality of care on their unit on what they perceive to be their task priorities.

- Units that are characterized by a clan culture provide better quality of care, both in the eyes of the nursing staff as in the eyes of outsiders. Market culture, compared to clan culture, is negatively related to quality of care in this study.

\section{BACKGROUND}

Organizational culture relates to the assumptions, values, attitudes, and beliefs that are shared among significant groups within an organization (Davies et al., 2007). In research on culture in general health care, many attempts have been made to elucidate any possible linkages between organizational culture and organizational performance (Davies et al., 2007). A strong, positive culture has been reported to contribute to quality of care (Deal et al., 1983). Yet, other studies in general health care report no associations at all (e.g. Hann et al., 2007).

A strong framework of organizational culture that is often applied in healthcare research ([Scott et al., 2003a] and [Scott et al., 2003b]) is the competing values framework (Cameron and Freeman, 1991). The competing values framework of organizational culture is a 4-quadrant model containing 4 value systems, i.e. culture types: clan, adhocracy, market, and hierarchy (see Fig. 1). Clan culture is characterized by shared values and goals, a strong cohesion, participation, and a sense of 'we-ness'. Adhocracy culture can adapt quickly to new opportunities and is prepared to deal with rapidly changing times. Market culture is highly results oriented and focuses on profitability, competitiveness and productivity. Hierarchy culture is characterized by structure, rules and centralized decisions.

\section{[FIGURE 1]}

The culture types relate to each other on two axes of value orientations. One axis concerns flexibility vs. control. Clan and adhocracy cultures are considered as flexible; they are held to emphasize decentralization and differentiation. On the other hand, market and hierarchy cultures are considered as control oriented value systems, which emphasize centralization and integration. The second axis regards internal vs. external focus. Clan and hierarchy cultures are held to have an internal focus: they are aimed at integrating and smoothing activities within the organization. The external focus of adhocracy and market cultures emphasizes improvement of the organization's competitive position within its environment. Each organization usually has more than one of these types of cultures ([Scott et al., 2003a] and [Scott et al., 2003b]).

Since the 1990s, several studies on organizational culture in long-term care are reported. A literature search was completed using the terms ((long-term care) OR (nursing home)) AND ((organizational culture) OR (organizational culture healthcare)) AND (nursing care). Many of the found publications regard research on safety culture in organizations (e.g. [Gruneir and Mor, 2008] and [Hughes and Lapane, 2006]), the relationship of culture with prescription of drugs (e.g. Hughes et al., 2007), or changing the culture of long-term care organizations into environments in which the residents' preferences and quality of life are central (e.g. [Ragsdale and McDougall, 2008] and [Fleshner, 2009]).

Relatively little is known about the relationship between organizational culture and quality of long-term care and studies found focus on different aspects of quality of care. Scott-Cawiezell et al. (2005) reported that clan and adhocracy cultures were important for successful improvement of care quality. Alternatively, in the explorative study of Wicke et al. (2004) it was found that working in a hierarchical, profit-making organizational culture was a significant barrier to effective teamworking and quality of care. Shortell et al. (2004) showed that maintaining a balance among the four culture types was important for perceived team 
effectiveness and having a greater focus on patient satisfaction. In their comprehensive review, (Scott et al., 2003a) and (Scott et al., 2003b) suggest that, although there may be a relationship between culture and organizational performance, articulating the nature of it is difficult. They propose a more nuanced association, in that specific aspects of performance are enhanced in those cultures that have values congruent with those aspects of performance ([Scott et al., 2003a], [Scott et al., 2003b] and [Davies et al., 2007]). For instance, the quality of various aspects of long-term care (as a measure for organizational performance) may be influenced by the degree to which nursing staff consider those aspects as task priorities.

In this study, the relationship between organizational culture and quality of long-term care on dementia units is investigated. Thereto, organizational culture is studied with regard to two measures of quality of care: the perceived quality of care by nursing staff and the observed quality of care by outsiders. In addition, following the suggestion of (Scott et al., 2003a) and (Scott et al., 2003b), the study focuses on those aspects of care considered to be task priorities by nursing staff. In the next sections, first the existence of the four culture types of the competing values framework on the dementia units is assessed. Second, quality of care and its relationship with organizational culture is studied.

\section{METHODS}

A cross-sectional design was used to guide this study. Data were gathered on dementia units of nursing homes in two days of field-work on each unit. During these days, systematic observations were performed, and questionnaires were distributed among nursing staff. Nursing staff could complete the questionnaire and return it by envelope to the researchers within two weeks. Care-requirements of residents were also assessed by nursing staff in the same period.

Ethical issues of the study were discussed. According to Dutch regulation no approval of an ethics committee for this study was necessary, as no intervention was investigated and data-collection was based on proxy-report and not collected directly from residents. Written informed consent was asked from legal representatives of all residents on the units. Data were only collected for those residents for whom written informed consent was obtained. In addition, client councils of the participating nursing homes were informed of the study in advance and anonymity and confidentiality for residents and nursing staff were guaranteed.

\subsection{Setting}

For this study, data were collected in 11 Dutch nursing homes during November 2006-January 2007 (Merten et al., 2007). In the Netherlands, there are approximately 325 nursing homes with 53,800 beds (Ribbe et al., 1997), which provide multi-disciplinary care for elderly residents with long-term, complex health problems (Ribbe, 1993). Nursing homes provide somatic (general) care and psychogeriatric care for people with dementia. In this study, nursing homes participated on a voluntary basis with one psychogeriatric unit in each facility. In the Netherlands, nursing staff in long-term care form an educationally diverse group of specialised registered nurses, certified nursing assistants (CNAs), and assistants without healthcare education. All nursing staff, irrespective of their education-level, were asked to complete the questionnaire.

\subsection{Measurements}

\subsubsection{Characteristics of units}

Information was collected about different characteristics of the units that may influence quality of care processes: high or low degree of staffing (Schnelle et al., 2004), number of nursing staff, number of residents (Boekhorst et al., 2009) and the average care-requirements of residents on the unit (Van Beek et al., 2004). Information on the degree of staffing, and the number of staff and residents were collected in an interview with the unit supervisor. Care-requirements of residents were determined by measuring their cognitive and physical functioning. Cognitive functioning was measured with the cognitive performance scale (CPS; Morris et al., 1994) of the Minimum Data Set (MDS) of the Resident Assessment Instrument (Morris et al., 1990). The CPS consists of 5 items and ranges from 0 (intact cognition) to 6 (very severe impairment). Problems in physical functioning were measured using the ADL (Activities of Daily Living) 
hierarchy index of the MDS (Morris et al., 1999). This scale consists of 4 items. The index ranges from 0 (independent) to 6 (totally dependent on others).

\subsubsection{Organizational culture}

Organizational culture was measured with the competing values framework of organizational culture (CVF) for long-term care as developed by Scott-Cawiezell et al. (2005). The CVF assesses the 6 dimensions of the competing values framework in 6 items. These are dominant organizational characteristic, administration, management style, organizational glue, strategic emphasis and criteria for success. The version of Scott-Cawiezell et al. (2005) was translated into Dutch, this translation validated through back translation. As nursing staff in Scott-Cawiezell's study found the CVF very complicated to complete (J. Scott-Cawiezell, personal communication), the response mode was adapted (see Appendix A for the instrument). Originally, respondents needed to distribute 100 points across 4 response options that each reflect a culture type, thereby weighing each option according to how closely they believe it fits their organization (Scott-Cawiezell et al., 2005). In this version, the 4 response options needed to be ranked from 1 to 4 , with 4 representing the characterization that best reflects how things work in their organization. This way, each culture type could have scores ranging from 6 to 24, which were recoded in scores ranging from 0 to 18.

\subsubsection{Quality of care}

Two different independent measurements of quality of care were considered: the perceived quality of care by nursing staff on the units and the observed quality of care on units by researchers. Especially those aspects of quality of care were observed, that were considered as task priorities by nursing staff.

Perceived quality of care was measured by asking nursing staff in the questionnaire how they rated the quality of care on their unit, with the question: 'What do you think, in general, of the quality of care that residents receive on your unit?'. Answers could be scored on a five-point scale varying between poor (1) and very good (5).

In addition, quality of care was observed at three times during two days on each unit. Observations were carried out by two people: one of the researchers and an employee of the nursing home, most often a psychologist or quality coordinator of the facility. For the observations, an observation-list of 32 items was used that focused on different aspects of the care for residents. The observation-list was derived from a list used by Van Oort and Wagner (2002) that, in turn, was based on the aspects of quality of care defined by Rantz et al. (1998). Each item was scored on a five-point scale, with 5 representing the most positive score. The observation-list was completed at three times. Observation-times were determined in advance and represented three important moments of care: morning (around $9.00 \mathrm{~h}$ ), dinner-time (around $12.00 \mathrm{~h}$ ), and the afternoon (around $15.30 \mathrm{~h}$ ). The times of observation were not known to nursing staff in advance. After an observation-period of 20-30 min, both observers individually completed the list and, afterwards, discussed their findings.

The aim was to connect the measures of quality of care to what nursing staff perceive as their most important tasks in dementia care. Thereto, nursing staff were asked to choose the three most important out of twelve nursing tasks in the questionnaire: creating safe and clean surroundings; observing changes in the residents' condition; restricted procedures; supporting residents emotionally; educating family members on disease processes and behaviour management; supporting family members emotionally; keeping care plans up to date; creating a nice and friendly atmosphere; engaging in activities with residents; getting family members involved in daily life on the unit; stimulating social engagement of residents, and delivering personal individual care. The list of tasks was based on an earlier study on quality of care for residents with dementia in the Netherlands in which unit supervisors were asked to define the most important aspects of quality of care for residents with dementia (Van Beek et al., 2004).

From the above-mentioned observation-list, those items were selected that corresponded to the three most important tasks mentioned by nursing staff. Eight items were thus selected. For each of the three different observation-moments, a score for each item was computed based on the average score of the two observers on each unit. A scale score was computed by adding the scores and dividing this by the number of items. Cronbach's alpha of the 8 items together was 0.69. 


\subsection{Data analysis}

To answer the research questions, data were analyzed in several steps. First, the correlation between the organizational culture and the measures of quality of care on the 11 units was studied. Second, to be able to control for characteristics of individual members of nursing staff and units, multilevel analyses ([Snijders and Bosker, 1999] and [Leyland and Groenewegen, 2003]) was carried out in MlwiN (Rasbash et al., 2004) with perceived quality of care by nursing staff as the main dependent variable. In Model 1, to control for nursing staff characteristics, age, gender, number of hours worked per week, and tenure on the unit of nursing staff were entered into the multilevel analyses on staff-level. These measures were centred on average. As the relationship between organizational culture and quality of care may also be influenced by the setting, the following structural characteristics of the units were entered, individually, into the analyses on unit-level: degree of staffing, problems in cognitive and physical functioning of residents (average CPS and ADL hierarchy score on the unit), number of nursing staff on the unit and number of residents on the unit (Model 2). Third, organizational culture was entered into the model after characteristics of nursing staff and significant characteristics of the unit (Model 3). Organizational culture was entered into the model on the level of individual members of nursing staff.

\section{RESULTS}

\subsection{Characteristics of nursing staff}

A total of 248 staff members completed the questionnaire, with an average response rate of $63 \%$ on the 11 units. Most nursing staff were female, with an average age of 39 years. Average hours worked was $24 \mathrm{~h}$ per week. All educational levels of nursing staff were represented in the respondents of this study, however, especially CNAs (46\%) returned the questionnaire. Tenure on the units was 5 years on average, varying between two weeks and 25 years. Respondents in this study did not differ from all nursing staff in the Netherlands (nurses and CNAs) in the percentage of females, and their average age (Van der Windt et al., 2004).

\subsection{Characteristics of the units}

Units were dichotomized into a high (score 1 ) and a low degree (score 0 ) of staffing. Four units, with more than 0.8 Full Time Equivalent (FTE) of qualified staff per resident, were assigned a score of one. Seven units, with less than 0.8 FTE per resident, were given a score of zero (Merten et al., 2007). On the 11 units, the number of nursing staff members varied between 21 and 51. The number of residents varied between 22 and 45. The average score for cognitive problems (CPS) was 4.3 ( $\mathrm{sd}=1.58)$; the average score on the ADL hierarchy scale was 3.7 ( $\mathrm{sd}=1.61$ ), indicating that, on average, the residents on the 11 units suffered from severe cognitive and physical problems. Scores on the CPS varied between 3.4 and 5.3 on the units; ADLscores varied between 2.8 and 4.3. The number and care-requirements of residents on the units in this study were similar to those of other psychogeriatric units in nursing homes in the Netherlands (Mathijssen et al., 2004).

\subsection{Organizational culture}

In Table 1 the results on organizational culture are presented for the 11 units. Clan culture is the strongest on average (mean 12.4). Market culture has the lowest average (4.5). The mean scores of the units vary significantly ( $<0.01$ on all 4 types). For every staff member, a dominant culture type was appointed by comparing the sumscores for each type. A dominant culture type for an individual staff member was appointed if one of the types had a higher score than the other three. In total, 56\% of nursing staff scored highest on clan culture, 28\% scored highest on hierarchy, 9\% scored highest on adhocracy and 7\% scored highest on market culture.

\section{[TABLE 1]}

\subsection{Quality of care}

In this study, quality of care was measured in two ways. First, the perceived quality of care by nursing staff was looked at. Overall, nursing staff were content with the quality of care on the unit. A total of $72 \%$ staff members indicated that the quality of care on their unit was good to very good; $7 \%$ indicated that the quality of care on the unit was mediocre to bad. The percentage of staff who found the care (very) good 
varied between $100 \%$ and $25 \%$ on the units; mediocre to bad varied between $0 \%$ and $31 \%$. The average score on quality of care was 3.8 ( $\mathrm{sd}=0.76$ ), varying between 2.7 and 4.1 on the 11 units.

Second, aspects of quality of care on the units were systematically observed. For this, nursing staff were first asked what they considered to be their main task responsibilities in dementia care. Delivering personal individual care (62\%), creating a nice and friendly atmosphere (57\%) and supporting residents emotionally (45\%) were most often named (see Table 2).

\section{[TABLE 2]}

From the observation-list, 8 items were selected that were closely related to these aspects: nursing staff start a friendly conservation with residents, nursing staff take sufficient time for residents, nursing staff treat residents with respect, nursing staff call residents by their name, nursing staff actively care for residents, nursing staff and residents seem at ease with each other, units have a nice and friendly atmosphere, and units make a lively impression. The average score on the items was $3.94(\mathrm{~N}=33)$ with a range of 3.13-4.50 (sd = 0.32).

The perceived quality of care by nursing staff was significantly correlated with the quality of care scale derived from the observations on the units. On units where nursing staff reported a better quality of care, researchers, independently from these findings, observed a higher quality of interaction between nursing staff and residents and a better atmosphere on the units (pmcc 0.53; $p<0.001$ ).

\subsection{The relationship between organizational culture and quality of care}

Table 3 shows the correlations between organizational culture and observed quality of care. Average clan and market culture types on the units were strongly correlated to both observed quality of care by outsiders and perceived quality of care by nursing staff. Clan was positively correlated to quality of care. Market, on the other hand, was negatively correlated to care quality. No correlation was found between adhocracy and hierarchy cultures and the observed quality of care by outsiders.

\section{[TABLE 3]}

As characteristics of units and nursing staff may influence the relationship between organizational culture and quality of care a multilevel analysis was executed. For this, the perceived quality of care by nursing staff was studied (see Table 4). In Model 1, to account for possible differences in nursing staff, characteristics of nursing staff were entered into the analysis. None of the characteristics were found to be significantly related to quality of care. However, when taking these characteristics into account, the variance in quality of care between units, increased with 3\% (ICC $=28 \%$ ). In addition, it was found that none of the characteristics of the units (Model 2) were significantly related to perceived quality of care. In Model 3, the relationship between organizational culture and quality of care was studied.

\section{[TABLE 4]}

Oganizational culture was found to be related to the perceived quality of care of nursing staff. Nursing staff who typified their units as market oriented indicated a lower quality of care on their units compared to nursing staff who identified their unit as clan oriented. No relationship was found between perceived quality of care and adhocracy and hierarchical oriented cultures. By adding organizational culture into the analyses, differences between units remained significant, indicating that there may be other unit characteristics that influence quality of care.

\section{DisCUSSION}

The aim was to study the relationship between organizational culture and quality of care in long-term care. For this, we used two independent measures of quality of care: the perceived quality of care by nursing staff and results from independent observations by third parties. Those aspects of quality of care were observed, that were considered to be task priorities by nursing staff. Nursing staff most often named delivering personal individual care, creating a nice and friendly atmosphere, and supporting residents emotionally as their main tasks. These tasks partly overlap with the findings of Schirm et al. (1999), who discovered that 
nursing staff in nursing homes considered a caring attitude, respect for residents and 'doing something extra' essential elements of quality of care.

Both perceived quality of care by nursing staff and observed quality of care by third parties were positively correlated. This finding is important as it shows that nursing staff indeed seem to base their judgment of quality of care on what they perceive to be their task priorities. Furthermore, the correlation between both outcomes suggests that nursing staff were able to assess the quality of care adequately, and perceived quality of care by nursing staff could be seen as a valid measure of care processes on the units.

Organizational culture was related to both perceived and observed quality of care on the units. Units that are characterized by a clan culture provide better quality of care, both in the eyes of the nursing staff as in the eyes of outsiders. In contrast, units with a market oriented culture provide less quality of care. No relationship was found between hierarchy or adhocracy culture and quality of care. To investigate if the relationship between organizational culture and quality of care was mediated by characteristics of nursing staff or units, a multilevel analyses was performed with perceived quality of care as the dependent variable. These results from these analyses confirmed the initial result that a market oriented culture, compared to clan culture, is negatively related to quality of care. There was no relationship found between characteristics of nursing staff, characteristics of units and quality of care in this sample.

In accordance with the study of Scott-Cawiezell et al. (2005), this study shows that clan culture is a positive feature with regard to care quality. Although adhocracy culture was shown to be important with regard to improvement of care quality (Scott-Cawiezell et al., 2005 J. Scott-Cawiezell, K. Jones and L. Moore, Nursing home culture: a critical component in sustained improvement, Journal of Nursing Care Quality 204 (2005), pp. 341-348. View Record in Scopus | Cited By in Scopus (12)Scott-Cawiezell et al., 2005), it appeared not to relate to quality of care in this study. Given that adhocracy is a culture type in which adapting to new circumstances is a central feature ([Scott et al., 2003a] and [Scott et al., 2003b]), its importance for changing care is evident. Possibly, however, it may not be as positive with regard to quality of care as such. The results of this study also did not confirm those of Wicke et al. (2004) that working in a hierarchical culture was a significant barrier to quality of care. Market culture was the only culture type that was negatively related to quality of care. It may not be beneficial for quality of long-term care to have a culture that is both control oriented and has an external focus, and it would be interesting to study whether job satisfaction plays a role in this.

The results should be interpreted with caution. First, a cross-sectional design on 11 units in nursing homes was used. As a result, the power of the multilevel analysis is restricted to 11 units at the highest level which means that organizational variables cannot be entered simultaneously into the model. The findings, which show no relationship between unit characteristics and quality of care, may be due to this power restriction. However, even on 11 units significant differences in the quality of care are found that are, in turn, significantly related to organizational culture. An adapted version of the CVF was used in this study, as the original scoring method was very complex, leading to many missing data (Scott, personal communication). Although this method implied a reduction in response options and variance, the study is consistent with earlier findings that organizations usually can be defined by more than one culture type ([Scott et al., 2003a] and [Scott et al., 2003b]) and that a strong clan culture is a positive feature of a unit ([Shortell et al., 2004] and [Scott-Cawiezell et al., 2005]). Further research using this adapted version could investigate whether the findings on the importance of a strong clan and adhocracy culture for quality improvement can be confirmed. In their study on perceived team effectiveness, Shortell et al. (2004) found that a balance between culture types was important. Reconstructing their measure on how evenly nursing staff distributed points across the 4 culture types (the highest score on the balance measure reflecting apportioned points in a 9/9/9/9 pattern in the present response mode), no relationship between a balance in culture and quality of care was found. It is yet unclear whether the conclusion should be that the relationship between culture and quality of care is not about balance, or that the alterations in the scoring method of the CVF were responsible for not finding a relationship.

Although culture was related to quality of care, variation between the units remained significant after organizational culture was entered into the analyses. Further study should focus on other characteristics of units that may explain differences in quality of care.

The results indicate that organizational culture in long-term dementia care is important for organizational performance. It is intriguing to find that a market oriented culture on the units is negatively related to quality of care in this study. At the moment, there is an emphasis on the use of market strategies in long- 
Beek, A.P.A. van, Gerritsen, D.L. The relationship between organizational culture of nursing staff and quaphty of care for residents with dementia: questionnaire surveys and systematic observations in nursing homes. International Journal of Nursing Studies: 2010, 47(10), 1274-1282

term care facilities in the Netherlands and it may be expected that this use of market strategies will increase distinctly in the next years. The results suggest that this development may not be beneficial to residents in long-term care when the market culture is applied to the units themselves, as both independent measures of quality of care are negatively related to a market oriented culture on the units.

In conclusion, the results of this study imply that organizational culture in long-term care is related to quality of care. Units that have a strong clan culture provide better quality of care than units with a market oriented culture, according to nursing staff as well as to independent observers. Furthermore, the opinion of nursing staff on the general quality of care that is provided on the unit, appears to be based on those tasks that they regard as priorities.

\section{ACKNOWLEDGMENTS}

The authors would like to thank Peter Spreeuwenberg, M.Sc., of the Netherlands Institute of health services research for his contribution to the multilevel analyses.

Conflict of interest: The authors have no conflicts of interest to declare.

Funding: This study was funded by ActiZ, the Dutch Organization of healthcare providers.

Ethical approval: None declared.

FIGURES AND TABLES

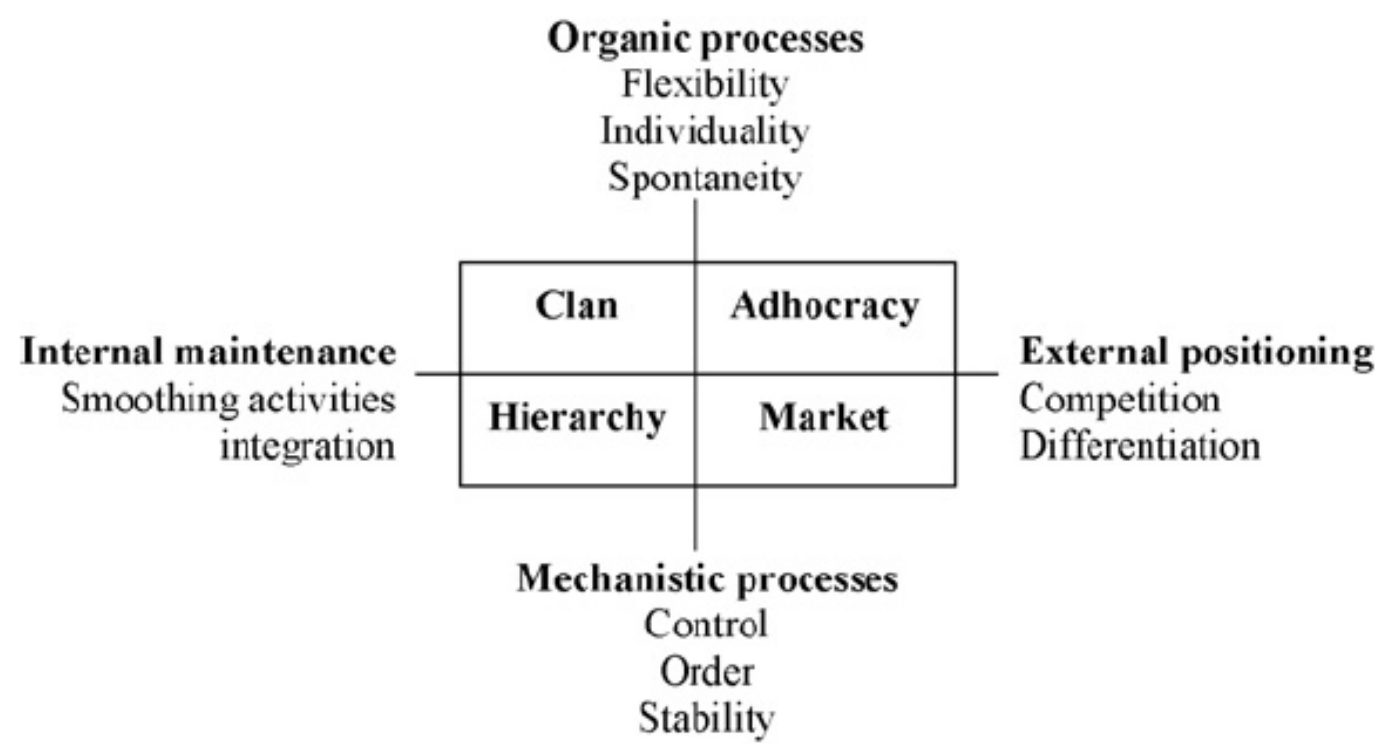

Fig. 1. The competing values framework of organizational culture. 
Beek, A.P.A. van, Gerritsen, D.L. The relationship between organizational culture of nursing staff and quahity of care for residents with dementia: questionnaire surveys and systematic observations in nursing homes International Journal of Nursing Studies: 2010, 47(10), 1274-1282

Table 1

Mean culture scores of the 11 participating units.

\begin{tabular}{llllc}
\hline & Clan & Adhocracy & Market & Hierarchy \\
$N=225$ & $N=226$ & $N=227$ & $N=227$ \\
\hline 1 & 13.3 & 9.1 & 3.9 & 9.5 \\
2 & 12.5 & 6.8 & 4.3 & 12.5 \\
3 & 11.2 & 7.9 & 5.8 & 11.1 \\
4 & 13.2 & 9.7 & 3.6 & 9.5 \\
5 & 14.3 & 9.4 & 2.5 & 9.9 \\
6 & 12.1 & 9.1 & 4.0 & 10.7 \\
7 & 15.0 & 8.3 & 2.9 & 9.8 \\
8 & 12.1 & 10.8 & 4.5 & 8.6 \\
9 & 12.4 & 7.7 & 4.2 & 11.7 \\
10 & 9.1 & 9.6 & 7.7 & 9.6 \\
11 & 10.2 & 9.7 & 6.1 & 10.1 \\
Mean & 12.4 & 8.7 & 4.5 & 10.4 \\
\hline
\end{tabular}

Table 2

Task priorities according to nursing staff on the 11 units $(N=249)$.

\begin{tabular}{lc}
\hline Task & $\%$ \\
\hline Delivering personal individual care & $62 \%$ \\
Creating a nice and friendly atmosphere & $57 \%$ \\
Supporting residents emotionally & $45 \%$ \\
Observing changes in residents' condition & $44 \%$ \\
Creating safe and clean surroundings & $29 \%$ \\
Keeping care plans up to date & $16 \%$ \\
Educating family members on disease & $12 \%$ \\
$\quad$ processes and behaviour management & \\
Engaging in activities with residents & $11 \%$ \\
Involving family members in the daily life on the unit & $11 \%$ \\
Stimulating social engagement of residents & $9 \%$ \\
Conducting restricted procedures & $7 \%$ \\
Supporting family members emotionally & $4 \%$ \\
\hline
\end{tabular}

Table 3

Correlations between perceived and observed quality of care, and organizational culture based on the three observation-moments on the 11 units $(N=33)$.

\begin{tabular}{|c|c|c|c|c|c|}
\hline & $\begin{array}{l}\text { Adhocracy } \\
\text { culture }\end{array}$ & $\begin{array}{l}\text { Market } \\
\text { culture }\end{array}$ & $\begin{array}{l}\text { Hierarchy } \\
\text { culture }\end{array}$ & $\begin{array}{l}\text { Perceived quality } \\
\text { of care by nursing staff }\end{array}$ & $\begin{array}{l}\text { Observed quality } \\
\text { of care by outsiders }\end{array}$ \\
\hline Clan culture & -0.170 & $-0.962^{* *}$ & -0.069 & $0.824^{* *}$ & $0.644^{* *}$ \\
\hline Adhocracy culture & & 0.124 & $-0.903^{* *}$ & $-0.380^{\circ}$ & -0.321 \\
\hline Market culture & & & 0.007 & $-0.783^{* *}$ & $-0.615^{* *}$ \\
\hline Hierarchy culture & & & & 0.166 & 0.154 \\
\hline Perceived quality of care by nursing staff & & & & & $0.532 *$ \\
\hline
\end{tabular}


Beek, A.P.A. van, Gerritsen, D.L. The relationship between organizational culture of nursing staff and quapity of care for residents with dementia: questionnaire surveys and systematic observations in nursing homes International Journal of Nursing Studies: 2010, 47(10), 1274-1282

Table 4

Multilevel analyses: the relationship between organizational culture and perceived quality of care by nursing staff $(N=229)$ on dementia units $(N=11)$.

\begin{tabular}{|c|c|c|c|}
\hline & Baseline model B (SE) & Characteristics of nursing staff $B(S E)$ & Organizational culture B (SE) \\
\hline Intercept & $3.706(0.126)$ & $3.70(0.132)$ & $3.762(0.131)$ \\
\hline \multicolumn{4}{|l|}{ Characteristics of nursing staff } \\
\hline Age & & $0.002(0.004)$ & $0.002(0.004)$ \\
\hline Female (ref: male) & & $-0.106(0.228)$ & $-0.110(0.225)$ \\
\hline Working hours a week & & $0.011(0.006)$ & $0.011(0.006)$ \\
\hline Employment on unit (in months) & & $-0.001(0.001)$ & $-0.001(0.001)$ \\
\hline \multicolumn{4}{|l|}{ Organizational culture } \\
\hline Adhocracy (ref: Clan) & & & $-0.040(0.157)$ \\
\hline Market (ref: Clan) & & & $-0.444(0.182)$ \\
\hline Hierarchy (ref: Clan) & & & $-0.100(0.103)$ \\
\hline \multicolumn{4}{|l|}{ Variance components } \\
\hline Units & $0.150(0.074)$ & $0.169(0.081)$ & $0.150(0.074)$ \\
\hline Nursing staff & $0.445(0.043)$ & $0.431(0.041)$ & $0.422(0.040)$ \\
\hline ICC units & $25 \%$ & $28 \%$ & $26 \%$ \\
\hline
\end{tabular}

Bold letter type indicates a significant association at $p<0.05$.

Appendix A. Scoring method and items of the CVF in this study

In this section, we provide six sets of four statements that describe the daily life on the unit. Would you order the statements on a range from 4 to 1 ? The statement that you agree with most gets 4 points, the statement with which you agree the least gets a score of 1 . The other two statements receive 2 and 3 points.

\section{Example}

This unit is:

A very personal place like belonging to a family

A very business-like place with lots of risk-taking

A very competitive place with high productivity

A very formal and structured place with lots of rules and policies

\section{This unit is:}

a very personal place like belonging to a family

a very business-like place with lots of risk-taking

a very competitive place with high productivity

a very formal and structured place with lots of rules and policies

\section{The unit supervisor is :}

like a coach, a mentor, or a parent figure

a risk-taker, always trying new ways of doing things

a hard driver; very competitive and productive

a good organizer, an efficiency expert 
Beek, A.P.A. van, Gerritsen, D.L. The relationship between organizational culture of nursing staff and quapity of care for residents with dementia: questionnaire surveys and systematic observations in nursing homes. International Journal of Nursing Studies: 2010, 47(10), 1274-1282

The management style at this unit is:

team work and group decision making

individual freedom to work in new ways

intense competition and getting the job done

job security, seniority system, and predictability

My unit is held together by:

loyalty, trust and commitment

a focus on customer service

emphasizing productivity, achieving goals, and getting the job

formal procedures, rules, and policies

The work climate on my unit:

promotes trust, openness, and people development

emphasizes trying new thing and meeting new challenges

promotes competition and achievement of targets and objectives

emphasizes tradition, stability, and efficiency

My unit defines success at:

team work and concern for people

being a leader in providing the best care

being number one when compared to other nursing homes

being efficient and dependable in providing services

\section{REFERENCES}

Boekhorst et al., 2009 S. te Boekhorst, M.F.I.A. Depla, J. de Lange and J.A. Eefsting, The effects of group living homes on older people with dementia: a comparison with traditional nursing home care, International Journal of Geriatric Psychiatry 24 (2009), pp. 970-978.

Cameron and Freeman, 1991 K. Cameron and S. Freeman, Culture, congruence, strength and type: relationship to effectiveness, Research in Organizational Change and Development 5 (1991), pp. $23-58$.

Davies et al., 2007 H.T.O. Davies, R. Mannion, R. Jacobs, A.E. Powell and M.N. Marshall, Exploring the relationship between senior management team culture and hospital performance, Medical Care Research and Review 64 (2007), pp. 46-65.

Deal et al., 1983 T. Deal, A. Kennedy and A. Spiegel, How to create an outstanding hospital culture, Hospital Forum 261 (1983), pp. 21-28 33-34.

Fleshner, 2009 M.K. Fleshner, Person-centered care and organizational culture in long-term care, Journal of Nursing Care Quality 24 (2009), pp. 273-276. 
Beek, A.P.A. van, Gerritsen, D.L. The relationship between organizational culture of nursing staff and quanty of care for residents with dementia: questionnaire surveys and systematic observations in nursing homes. International Journal of Nursing Studies: 2010, 47(10), 1274-1282

Gruneir and Mor, 2008 A. Gruneir and V. Mor, Nursing home safety: current issues and barriers to improvement, Annual Review of Public Health 29 (2008), pp. 369-382.

Hann et al., 2007 M. Hann, P. Bower, S. Campbell, M. Marshall and D. Reeves, The association between culture, climate and quality of care in primary health care teams, Family Practice 244 (2007), pp. 323329.

Hughes et al., 2007 C.M. Hughes, K. Lapane, M.C. Watson and H.T. Davies, Does organizational culture influence prescribing in care homes for older people? A new direction for research, Drugs and Aging 242 (2007), pp. 81-93.

Hughes and Lapane, 2006 C.M. Hughes and K.L. Lapane, Nurses' and nursing assistants' perceptions of patient safety culture in nursing homes, International Journal of Quality in Health Care 184 (2006), pp. 281-286.

Leyland and Groenewegen, 2003 A.H. Leyland and P.P. Groenewegen, Multilevel modelling and public health policy, Scandinavian Journal of Public Health 31 (2003), pp. 267-274.

Mathijssen et al., 2004 S.W. Mathijssen, A.J.J. Kwartel and C.G.M. van der Pepels, Brancherapport Care 2000-2003, Ministerie van Volksgezondheid, Welzijn en Sport, Den Haag (2004).

Merten et al., 2007 H. Merten, A.P.A. van Beek, D.L. Gerritsen, M.P. Poortvliet, J.R.J. de Leeuw and C. Wagner, Dagelijkse bezetting van personeel en de kwaliteit van leven van bewoners met psychogeriatrische problemen, Adequacy of Staffing and Quality of Life for Residents with Psychogeriatric Problems, NIVEL, Onderzoeksrapport, Utrecht (2007).

Morris et al., 1994 J.N. Morris, B.E. Fries, D.R. Mehr, C. Hawes, C. Phillips, V. Mor and L.A. Lipsitz, MDS Cognitive Performance Scale, Journal of Gerontology Medical Sciences 49 (1994), pp. M174-M182.

Morris et al., 1999 J.N. Morris, B.E. Fries and S.A. Morris, Scaling ADL's Within the MDS, Journal of Gerontology: Medical Sciences 54 (1999), pp. M546-M553.

Morris et al., 1990 J.N. Morris, C. Hawes and B.E. Fries, Designing the national resident assessment instrument for nursing homes, The Gerontologist 30 (1990), pp. 293-307.

Ragsdale and McDougall, 2008 V. Ragsdale and G.J. McDougall, The changing face of long-term care: looking at the past decade, Issues in Mental Health Nursing 29 (2008), pp. 992-1001.

Rantz et al., 1998 M.J. Rantz, D.R. Mehr, L. Popejoy, M. Zwygart-Stauffacher, L.L. Hicks, V. Grando, V.S. Conn, R. Porter, J. Scott and M. Maas, Nursing home care quality: a multidimensional theoretical model, Journal of Nursing Care Quality 12 (1998), pp. 30-46.

Rasbash et al., 2004 J. Rasbash, F. Steele, W. Browne and B. Prosser, A User's Guide to MLwiN, Version 2. 0. Multilevel Models Project, Institute of Education of the University of London (2004).

Ribbe et al., 1997 M.W. Ribbe, G. Ljunggren, K. Steel, E. Topinkova, C. Hawes, N. Ikegami, J.C. Henrard and P.V. Jonnson, Nursing homes in 10 nations, a comparison between countries and settings, Age and Ageing 26 (S2) (1997), pp. 3-12.

Ribbe, 1993 M.W. Ribbe, Care for the elderly: the role of the nursing home in the Dutch Health care system, International Psychogeriatrics 5 (1993), pp. 213-222.

Schnelle et al., 2004 J.F. Schnelle, S.F. Simmons, C. Harrington, M. Cadogan, E. Garcia and B.M. BatesJensen, Relationship of nursing home staffing to quality of care, Health Services Research 39 (2004), pp. 225-250.

Schirm et al., 1999 V. Schirm, T. Albanese and N.T. Garland, Understanding nursing home quality of care: incorporating caregivers' perceptions through structure, process and outcome, Quality Management in Healthcare 8 (1999), pp. 55-63.

Scott et al., 2003a T. Scott, R. Mannion, H. Davies and M. Marshall, The quantitative measurement of organizational culture in health care: a review of the available instruments, Health Services Research 383 (2003), pp. 923-945.

Scott et al., 2003b T. Scott, R. Mannion, M. Marshall and H. Davies, Does organizational culture influence health care performance? A review of the evidence, Journal of Health Services Research \& Policy 82 (2003), pp. 105-117.

Scott-Cawiezell et al., 2005 J. Scott-Cawiezell, K. Jones and L. Moore, Nursing home culture: a critical component in sustained improvement, Journal of Nursing Care Quality 204 (2005), pp. 341-348.

Shortell et al., 2004 S.M. Shortell, J.A. Jarsteller, M. Lin, M.L. Pearson, S.Y. Wu, P. Mendel, S. Cretin and M. Rosen, The role of perceived team effectiveness in improving chronic illness care, Medical Care 42 (2004), pp. 1040-1048.

Snijders and Bosker, 1999 T.A.B. Snijders and R.J. Bosker, Multilevel Analysis: An Introduction to Basic and Advanced Multilevel Modelling, Sage publications, London (1999).

Van Beek et al., 2004 A.P.A. Van Beek, C. Wagner, D.H.M. Frijters, P.M.M. Spreeuwenberg, P.P. Groenewegen and M.W. Ribbe, Kwaliteit van zorg voor ouderen met psychogeriatrische problemen in 
Beek, A.P.A. van, Gerritsen, D.L. The relationship between organizational culture of nursing staff and quapity of care for residents with dementia: questionnaire surveys and systematic observations in nursing homes International Journal of Nursing Studies: 2010, 47(10), 1274-1282

verpleeg-en verzorgingshuizen, Quality of Care for Residents with Psychogeriatric Problems in Nursing Homes and Residential Homes, NIVEL, Onderzoeksrapport, Utrecht (2004).

Van der Windt et al., 2004 W. Van der Windt, H. Calsbeek, H. Talma and L. Hingstman, Feiten over verpleegkundige en verzorgende beroepen in Nederland, Facts on Nursing Occupations in the Netherlands in 2004, Elsevier gezondheidszorg, Maarssen (2004).

Van Oort and Wagner, 2002 M. Van Oort and C. Wagner, Een exploratieve studie naar kosten en effecten van kwaliteitssystemen in zes verpleeg- en verzorgingshuizen, An explorative study on costs and effects of quality systems in six nursing homes and residential homes, Tijdschrift Voor Gezondheidswetenschappen 6 (2002), pp. 393-399.

Wicke et al., 2004 D. Wicke, R. Coppin and S. Payne, Teamworking in nursing homes, Journal of Advanced Nursing 452 (2004), pp. 197-204. 